\title{
Flexibility in educational systems - Concept, indicators, and directions for future research
}

Citation for published version (APA):

Wessling, K., \& van der Velden, R. (2021). Flexibility in educational systems - Concept, indicators, and directions for future research. Maastricht University, Graduate School of Business and Economics. GSBE Research Memoranda No. 006 https://doi.org/10.26481/umagsb.2021006

Document status and date:

Published: 06/04/2021

DOI:

10.26481/umagsb.2021006

Document Version:

Publisher's PDF, also known as Version of record

\section{Please check the document version of this publication:}

- A submitted manuscript is the version of the article upon submission and before peer-review. There can be important differences between the submitted version and the official published version of record.

People interested in the research are advised to contact the author for the final version of the publication, or visit the DOI to the publisher's website.

- The final author version and the galley proof are versions of the publication after peer review.

- The final published version features the final layout of the paper including the volume, issue and page numbers.

Link to publication

\footnotetext{
General rights Owners
rights.

- You may freely distribute the URL identifying the publication in the public portal. please follow below link for the End User Agreement:

www.umlib.nl/taverne-license

Take down policy

If you believe that this document breaches copyright please contact us at:

repository@maastrichtuniversity.nl

providing details and we will investigate your claim.
}

Copyright and moral rights for the publications made accessible in the public portal are retained by the authors and/or other copyright owners and it is a condition of accessing publications that users recognise and abide by the legal requirements associated with these

- Users may download and print one copy of any publication from the public portal for the purpose of private study or research.

- You may not further distribute the material or use it for any profit-making activity or commercial gain

If the publication is distributed under the terms of Article $25 \mathrm{fa}$ of the Dutch Copyright Act, indicated by the "Taverne" license above, 
Katarina Wessling,

Rolf van der Velden

Flexibility in educational systems - Concept, indicators, and directions for future research

$\mathrm{RM} / 21 / 006$

ISSN: $2666-8807$

\section{GSBE}

Maastricht University School of Business and Economics

Graduate School of Business and Economics

\section{P.O Box 616}

NL-6200 MD Maastricht

The Netherlands 


\section{Flexibility in educational systems - Concept, indicators, and directions for future research}

Katarina Weßling1 2 and Rolf van der Velden ${ }^{1}$

\section{ABSTRACT}

This conceptual contribution discusses the idea of flexibility of educational systems from a multidisciplinary perspective. We define flexibility as possibilities that are provided by an education system to modify standard (predetermined) learning paths, which result from the structured organization of education. Flexibility at the macro level (i.e., educational system) can relate to policies such as the mobility between educational tracks within stratified systems. At the meso level (i.e., school, classroom), flexibility can entail practices of differentiated instruction. We believe that a systematic integration of flexibility in educational research can provide new insights on individuals' educational outcomes. Implicitly and unconnectedly, the idea of flexibility exists in several strands of research, typically focusing on educational-system effects on individual outcomes such as (1) sociological research on structural features of the education system, (2) psychological literature on educational effectiveness, and (3) economic research drawing on the education production function. We bridge these three fundamental strands of research with the aim to exemplify the concept of flexibility. In doing so, we propose a definition of flexibility, outline dimensions as well as corresponding indicators. To conclude, we provide some directions for future research.

Key words: flexibility, education systems, educational effectiveness, education production function macro-meso-micro model

${ }^{1}$ Research Centre for Education and the Labour Market (ROA), Maastricht University

P.O. Box 616

NL-6200 MD Maastricht

+31433882842

k.wessling@maastrichtuniversity.nl

r.vandervelden@maastrichtuniversity.nl

2 Federal Institute for Vocational Education and Training (BIBB)

Robert-Schuman-Platz 3

D-53175 Bonn

T +492281072723

katarina.wessling@bibb.de

Acknowledgements: This work is part of the project "How the flexibility of the Dutch educational system affects (social inequality in) educational outcomes", which is financed by the Netherlands Initiative for Education Research (NRO). We would like to thank Tim Huijts, Kars van Oosterhout, Dinand Webbink, Christoph Janietz, Roxanne Korthals, Per Bles, Melline Somers, Steffen Hillmert, and Dominik Becker for helpful comments. 


\section{Introduction}

The basic question in organizing education is: How can we guarantee that all students learn in such a way that they can reach their full potential, while at the same time being restrained by limited resources in the organization of education? An ideal-typical system would take every student's ability at every point in time in their educational career into account and offer educational input in line with Vygotsky's "zone of proximal development" (Kozulin et al., 2003). The optimal education system would hereby consider that students' learning potential and their developments are heterogeneous. However, time and budget constraints restrict the possibilities of individualized education and learning offers. Thus, education systems are arranged in a (more or less) formalized way, primarily focusing on the average student.

A large body of literature in the social sciences addresses the question of how the overall organization of education systems (macro level) and the organization oflearning on the school and classroom level (meso level) addresses the tension between individual students' needs on the one hand, and structural restrictions on the other hand. Frequently analyzed characteristics of education systems at the macro level are standardization and stratification (Allmendinger, 1989; Shavit and Mueller, 1998; van de Werfhorst and Mijs, 2010) ${ }^{1}$. However, when looking at effects of these characteristics on individual educational outcomes such as the overall level of performance, evidence is often mixed. A different strand of literature focusses on school effectiveness at the meso level (e.g., Hattie, 2008; Kyriakides and Creemers, 2008; Teddlie and Reynolds, 2000). The problem here is that this strand of literature often does not incorporate how processes at the meso level are constrained by the structural features at the macro level, leading to mixed findings as well.

We argue that both caveats are partly due to an overlooked feature: The flexibility potential of an education system. We define flexibility as possibilities to change (prior) decisions and actions, which resulted from the structured organization of education. We focus on institutionally provided modifications, i.e., the leeway for changing standard learning paths for individuals throughout their educational career that are explicitly facilitated by the education system (i.e., macro level) and the organization oflearning in schools and classrooms (i.e., meso level).

\footnotetext{
${ }^{1}$ A third feature of educational systems that is frequently discussed is vocational orientation (Shavit and Mueller, 1998; van de Werfhorst and Mijs, 2010). Since our concept of flexibility concerns predominantly primary and secondary general education, and not the relation of the education system and the labor market, we discuss flexibility in the following against the background of standardization and stratification.
} 
An example at the macro level is the possibility to change an educational track or ability group after students have been placed in distinct educational tracks or ability groups. A binary distinction between tracked and non-tracked systems falls short of the extent, frequency, and the manner at which education systems re-evaluate the initial track placement of students and enable them to change the track. For instance, while one educational system might be characterized by clear and strict rules under which upward or downward track mobility is possible (e.g., certain GPA), another system might in principle enable track changes without clear rules and regulations (e.g., based on student's or parent's choices), while yet other systems might not facilitate track mobility at all. As a consequence, the organization of track mobility in an educational system might affect the practices of track placement in the first place. At the meso level, forms of differentiated instruction and teaching such as tools that respond to a student's individual learning capacity but also additional learning opportunities such as summer schools or extra tutoring can also be considered examples of flexibility in education. All instruments representing flexibility have in common that they are geared towards modifying predefined learning paths with the aim to (more or less continuously) adjust the organization of education to a student's current educational need.

Although measures relating to flexibility have been studied separately (e.g., Hillmert, 2004; Kyriakidis and Creemers, 2008), previous research failed to make them an explicit and overarching concept. This is partly because different lines of research that refer to flexibility measures operate isolated from one another. These isolated perspectives obstruct a systematic view on the relationship between measures that map the flexibility potential at different levels of the education system. For instance, the possibility of track mobility (macro) could be considered as an instrument of flexibility, with the aim to adjust the track placement to a student's current performance level and thereby modify the student's educational path, while instruments such as summer schools or extra tutoring (meso) could be considered as an alternative but also in addition to changing a school track. Because these instruments are applied at different levels of the education system they are usually studied in isolation. Thus, we argue in favor of an integrative perspective that relates these instruments at meso and macro level since they are provided by an education system with the same aim: adjusting a student's learning path in order to account for the cognitive development and the current state of performance. We identify three research strands of literature that (more or less) implicitly reference flexibility; (1) sociological research on structural features of the education system, (2) psychological literature on educational effectiveness, and (3) economic research on the allocation of a system's resources based on the education production function. In this paper, we aim to bridge these three strands of research with the aim to come up with an overarching concept of flexibility. In doing so, 
the paper proceeds as follows: In the next section, we discuss the idea of flexibility and how it is (more or less) implicitly embedded in three strands of literature in question. In section three, we describe empirical research that deals with distinct aspects of flexibility. Following this, we propose systematic dimensions and corresponding indicators that map flexibility. Subsequently, we propose some directions for future research. In the final section, we will summarize the pros and cons of our concept and provide some concluding remarks.

\section{Flexibility in a multidisciplinary perspective}

Understanding the effect of the organization of education systems on individual educational outcomes requires a multilevel perspective in the tradition of the structural-individualistic scheme most prominently represented by "Coleman's boat model" (cf. Coleman 1990). The central idea of this approach is that macro-level conditions structure the possible courses of action that individuals can take at the micro level. In turn, these individual actions affect social outcomes at the macro level. Based on the idea that the meso level of institutions-in our case represented by the organization of learning in schools and classrooms-mediates the link between macro (system) and micro (individual) level, we follow up on the concept of Gross et al. (2016) which explicitly integrates the meso level in a "macro-meso-micro-model of education systems" (see Figure 1).

\section{FIGURE1 ABOUT HERE}

This is particularly relevant for flexibility because-following the example of track mobility versus extra tutoring or summer schools-specific instruments at macro and meso level of education can be complementary or supplementary. Thus, characteristics at the two levels should not only be observed separately but in the form of specific configurations if we want to understand how the education system affects educational outcomes at the micro level.

\section{1 (Mostly) Sociological research on features of the education system}

Particularly since cross-country data such as PISA is available a large body of empirical research has focused on comparing features at the macro level and their effects on core functions of education (e.g., 
Ammermüller, 2013; Bol and van de Werfhorst, 2016; Korthals, 2015; Pfeffer, 2015; van de Werfhorst and Mijs, 2010). In the seminal work by Allmendinger (1989), a typology of education systems along two key features-stratification and standardization-has been provided.

Stratification represents "the proportion of a cohort that attains the maximum number of school years [...] coupled with the degree of differentiation within given educational levels (tracking)." (Allmendinger, 1989: 233) In other words, stratification is the hierarchical structure of an education system. Indicators such as age at tracking and number of tracks are most prominent in measuring stratification. Against the background of stratification, flexibility is best described as the possibility of track mobility within educational careers. Standardization is characterized by "the degree to which the quality of education meets the same standards nationwide" (Allmendinger 1989: 233). A further differentiation refers to input versus output standardization (Bol and van de Werfhorst, 2013). Input standardization describes the degree to which the same curriculum such as learning material and teaching practices are applied. Output standardization refers to the degree to which central norms for examinations and grading practices are practiced. Prominent measures of standardization are the overall autonomy of schools in curriculum organization, examinations, and grades, but also the organization of teacher training, salaries, and other budgetary issues. The link between macro and meso level is relevant regarding the relationship between standardization and flexibility because standardization influences whether practices of flexibility are more likely to be implemented at the macro or the meso level. A high level of school autonomy suggests more possibilities to apply flexible learning such as differentiated instruction and teaching practices at the school or classroom level. Thus, specific practices at the level of schools become more relevant when the education system is less standardized.

Empirical findings suggest that potential desirable effects of the key features of the educational structure on some of the core functions of education-equality of opportunity, sorting and selecting students, providing labor-market relevant skills, and preparing students to become active citizenscan have undesired effects on other functions. Thus, the effects of the educational structure depend on the outcome observed (van de Werfhorst and Mijs, 2010). This is relevant for our framework, since the flexibility might subvert the relationship between the structure and the core functions of education. Empirical evidence supports this; research on the effects of stratification on the overall performance as well as on performance variations show mixed results. While some studies find that the variation in performance increases much stronger in systems with strong stratification (Hanushek and Wößmann, 2005), others do not find an impact of stratification on performance variation and overall performance (Brunello and Checchi, 2007). Empirical findings on 
standardization also suggest mixed patterns. Some authors find that the degree of school autonomy increases the effect of social origin and increases the overall level of performance (Hanushek and Wößmann, 2005). In turn, other authors suggest that school autonomy decreases average performance (Dronkers and Robert, 2008). In contrast to that, specific country examples such as Finland, which is often considered the "model student" of education systems because it combines a high level of overall performance with a low level of inequality is typically characterized by a large degree of school autonomy (Morgan, 2014). Overall, empirical evidence on the effects of the key features of education systems is thus mixed and the effect sizes are rather small. In a recent review, Allmendinger (2016) states that standardization and stratification are not sufficient to characterize education systems "simply because the two key dimensions underspecify what happens at schools" (Allmendinger, 2016: 332). Following this line of reasoning, we argue that focusing on different levels simultaneously is important as it provides the possibility to integrate structure-standardization and stratification-with process - practices in schools or classrooms.

\subsection{Psychological research on school effectiveness}

Educational psychology provides us with two important conceptual arguments. First, an in-depth view on what is going on in schools and classrooms. Second, an explicit notion on the development of cognitive ability over time, which is relevant since our understanding of modifying learning paths involves the idea of changes.

Routed in a psychological tradition, educational effectiveness research is focused on cognitive and non-cognitive outcomes (i.e., motivation, metacognition, and behavior) and less on (social) inequality in education. The attention of this research perspective lies at the meso level of schools and classrooms. In sociological research, characteristics at the meso level remain often underspecified and are rarely applied empirically. The validity of our idea of flexibility lies in substantiating the argument that factors at the meso level can substitute or complement factors at the macro level. Frequently addressed institutionally-relevant ${ }^{2}$ school and classroom factors are: curricular quality, leadership qualities of principals and teachers, performance measurements and evaluation, teacher consensus and cooperation, parental involvement, differentiation and adaptive instruction, private versus public schooling, denomination of schools, feedback practices, instruction time, student-teacher ratio, financial situation of schools (e.g., Creemers and Reezigt, 1996; Scheerens and Bosker, 1997; Teddlie and Reynolds, 2000). In his widely acknowledged meta study Hattie (2008) provides an

\footnotetext{
2 A large number of studies in educational effectiveness research focus on compositional effects such as school and classroom climate and socioeconomic or performance composition in schools and classrooms. These factors are not included here because we are interested in institutional effects. As such, we focus on instruments that are deliberately provided by the school or the teacher and that are part of the organization of education.
} 
extensive overview of factors. He developed an approach of synthesizing factors according to their effect size. Overall, more than 100 factors in seven areas-student, home, classroom, school, curricula, teacher, and teaching and learning approaches-are ranked. School and classroom factors are important when focusing on flexibility because adaptations towards individual needs at a specific point in the educational career are more easily applied at the meso level, for instance, in the form of differentiation and adaptive instruction. However, educational effectiveness research states that there is no "one size fits all"-practice. School and classroom factors that increase effectiveness differ for different outcomes such as cognitive and non-cognitive abilities or different school subjects (Scheerens and Bosker, 1997). More recent studies relate characteristics in order to analyze their relations and joint relevance in the dynamic model of educational effectiveness (DMEE; Kyriakides and Creemers, 2008). The DMEE does not only refer to various factors of effectiveness but more importantly suggests that each factor can be defined and measured according to five distinct dimensions, which are frequency, focus, stage, quality, and differentiation. The dimension of differentiation - the extent to which factors are implemented in the same way for all studentsrepresents what we understand as flexibility on the meso level. It refers to the idea of adjusting the organization of learning at the school and classroom level (Kyriakides and Creemers, 2008: 186f.). Differentiation is strongly based on concepts of differentiated instruction and adaptive teaching (Tomlinson, 2014).

Particularly when focusing on the possibilities to modify predetermined learning paths across the individual educational career, a cognitive developmental perspective is worth considering (Piaget, 1952; Denney, 1984). Cognitive and non-cognitive educational outcomes are not fixed traits but are dynamic and follow a specific developmental pattern. Empirical research provides evidence for the fact that the malleability of different types of abilities varies with age (Knudsen et al., 2006). A prominent example is the critical age in the acquisition of a second language. The fastest achievement and the highest level of proficiency is reached before the age of twelve (Collier, 1989). Thus, it seems to matter when in the educational career forms of flexibility are applied. It could, for instance, be possible that additional teaching and individual support instead of placing a student in a different ability group or track might be more beneficial at one point in the educational career, while a change of group or track could be beneficial at another point in the life course. While school and classroom indicators are considered in detail in psychological research, the macro level is often neglected. We argue that linking them is crucial also from the psychological perspective because school-level and classroom-level factors become particularly relevant when the degree of standardization is low. 


\subsection{Economics of education - the education production function}

In the economic literature, the overarching question on how optimal learning can be organized, while at the same time being restrained by limited resources is addressed in a more formalized way in the education production function (Hanushek, 1979). Empirical research typically focuses on measures of performance as the outcome of interest. Indicators such as school performance are considered relevant predictors of future capabilities on the labor market. In its general form, it is suggested that the output of education is a function of different inputs (Hanushek 1979).

$A=f(B, S, N, E)$

In several empirical applications the factors in the education production function were altered and extended (e.g., Ammermüller, 2013; Brunello and Checchi, 2007; Wößmann, 2016). Wößmann (2016) explicitly separates institutional from school factors. He differentiates three types of input factors: family background (B), school factors (S), and institutional structures of education systems ( $N$ ) as well as resources outside the education system (E) that are employed to explain measures of school output such as educational attainment or performance $(A)$. The institutional structure relates to the features of education systems, such as standardization and stratification (see above). Economic studies that incorporate measures of school resources in addition to standardization and stratification, often fail to achieve statistical significance. Sometimes they even provide counterintuitive results. Wößmann (2016), for instance, finds larger class size to show a positive effect on the overall level of performance while other cross-country studies find positive effects of smaller classes at least for a few number of countries (Altinok and Kingdon, 2012). Thus, while this line of research explicitly integrates the macro with the meso level, it lacks an explicit concept and results are often unclear. We argue that potential interrelations between factors on the different levels might be overlooked. This is particularly relevant when factors can be substitutes as argued earl in the example of track mobility versus extra tutoring or summer schools. The central lesson to be learned from the economic production function is the formalized perspective on resources at the macro and the meso level that represent educational input. The formalization provides us with the opportunity to integrate the two levels. We argue that factors of the educational system on macro and meso level can be integrated by subsuming them under two very general categories; content $(C)$ and input time $(T)$. By relating factors at both levels to time and content, we are able to observe how indicators at the two levels can substitute each other. Thus, students' educational outcomes can be framed as a function of content (C) and input time (T). Resources outside the education system (E) additionally affect students' educational outcomes such as the family, neighborhood, and peers.

$A=f(T, C, E)$ 
In the framework of the education production function, our idea of flexibility is not a new concept and can best be described as reallocation of input factors. To illustrate this, we refer to the aforementioned example; summer schools or extra tutoring (meso level) for students that lag behind can represent an alternative to downgrading from an educational track (macrolevel). The instruments are located at different levels of the education system but aim at providing students with more input time (T) to incorporate the same content $(C)$ in order to meet the objectives of their current educational stage.

\subsection{How do we define flexibility and why do we need it?}

To sum this up, we discussed three strands of literature all of which provide (more or less explicitly) an idea of flexibility in education:

i) From a sociological perspective, flexibility represents the notion that structural features like standardization and stratification can be implemented more or less rigidly. It thus cuts across the structural features of standardization and stratification. Against the background of stratification, flexibility is best described as track mobility in the educational career. The link between macro and meso level is particularly relevant when the degree of standardization is low because then flexibility is more likely and more easily applied at the meso level. Thus, outlining the idea of flexibility requires to integrate the different institutional levels of the education system. In that sense, a lowerdegree of standardization can be a precondition for flexibility at the meso level.

ii) At the meso level of schools and classrooms, flexibility is represented by the dimension of differentiation; the degree to which instruments are implemented that allow for treating students differently according to their individual needs. In addition, the psychological perspective emphasizes that types of skills are differently malleable at different ages, which indicates that different types of flexibility are more or less beneficial at a certain stage of the educational career.

iii) From the education production function, we derive a formalized model in which content (C) and input time $(T)$ are the resources that are allocated through the organization of education. In this framework, flexibility describes the reallocation ofresources.

We define flexibility under a common denominator that integrates the three research perspectives as leeway for changes in standard learning pathways for individuals throughout their educational career that are explicitly facilitated by the education system (i.e., macro level) and the organization oflearning in schools and classrooms (i.e., mesolevel). Note that our concept of flexibility does not refer to internal 
systemic changes or a systems' response to externalities such as a sudden increase or decline of the number of students.

It is important to realize that flexibility does not by definition lead to better outcomes for all functions of education. Like van de Werfhorst and Mijs (2010) argue, some characteristics may increase certain outcomes but at the expense of others. This also holds for flexibility. Ideal-typically, flexibility like any other feature of an education system at the macro or meso level is implemented with the intention to provide optimal results on all dimensions of individuals' educational outcomes. Thus, a high degree of flexibility could be beneficial as it offers possibilities for students to catch up on missed opportunities at previous stages in their education career. But a higher degree of flexibility (i.e., in the form of possibilities for changing tracks or catching up on educational degrees) also requires more knowledge about the education system, which can be expected to have negative consequences for students from low social origin. Therefore, more flexibility might increase the social inequality in educational outcomes. Moreover, modifying decisions along the educational career does not necessarily imply that the initial decision was necessarily wrong at the time it was made. For instance, placing a student into a specific school track according to his or her performance at a specific point in the educational career can turn out to be wrong at a later point in the educational career due to the performance development of the student, but it might still be the best track placement at the time the decision was made.

The value added of this multidisciplinary perspective is that by explicitly defining flexibility, we are able to strengthen a more explicit integration of the meso and the macro level of education. Beyond that, we demonstrate that seemingly unrelated aspects of the educational organization at the macro and the meso level are in fact part of the same concept. In that sense, understanding flexibility as the overarching concept allows us to observe that macro and meso level instruments can be deployed as substitutes. Also, integrating flexibility as a concept in empirical research might be helpful to understand why education systems that are similar in frequently observed features such as stratification and standardization provide differences in individual educational outcomes. Idealtypically our concept of flexibility refers to opportunities to change predefined learning paths that are provided by the education system and as such these measures are purposive elements in the organization of education, yet it is possible to empirically observe the occurrence of changes in learning paths that are not explicitly implemented as part of the educational organization - referring for instance to loopholes in the organization of education. It is an empirical question to quantify the extent to which unintended forms of flexibility exist in different education systems and to answer the 
question why they exist and if it is reasonable - for instance because the share of students that make use of it is considerably large - to consider them as part of the flexibility of an educational system .

\section{Dimensions and indicators of flexibility}

We propose dimensions of flexibility and indicators to measure them, which serve as a basis for an analytical integration of the concept. The indicators for the four dimensions of flexibility can be interrelated. Figure 2 illustrates the construct, dimensions, and indicators comprising flexibility.

\section{FIGURE 2 ABOUT HERE}

\subsection{Flexibility at the macro level}

The extent to which educational mobility is possible, relates to flexibility at the macro level of the education system. From the system's perspective, they are designed to keep learning groups over time as homogenous as possible. From the individual's perspective, these measures aim at presenting students with the most appropriate degree of academic challenge. A large body of research has focused on the initial sorting (tracking) of students. However, tracking or grouping of students may or may not be accompanied by the possibility of track mobility. While this does not change the stratification as such, it might affect the effects of stratification on outcomes and beyond that on the perception of students and parents on how serious the consequences of initial track placement are. While this may be obvious, it has not yet been systematically considered.

\section{Internal mobility}

First, we understand internal mobility as the possibility of corrective actions within an educational group or track. It refers to the mobility of an individual within the school system without changing hierarchically-structured groups or tracks. Prominent practices of internal mobility are (grade) repetition or retention and (grade) acceleration. Both measures refer to the reallocation of input time (T) since more time with the same content is provided for students performing below a certain threshold (retention) and less time with same content is provided for students performing above average (acceleration). Regulations concerning acceleration and retention vary greatly between education systems. While in some countries only an entire 
academic year can be skipped or repeated (e.g., Germany, the Netherlands), other countries such as the US offer the possibility of single-subject acceleration or retention in addition. Early school enrollment and redshirting-i.e., postponing the entry to the first grade of kindergarten or school-represent special forms of internal mobility.

With less than $1 \%$ of students affected in countries such as the Netherlands, Germany or Ireland acceleration is overall a rarely applied practice (Gross and van Vliet, 2005). Nevertheless, there are considerable country differences. In contrast to most European countries, "radical acceleration" is applied as a form of gifted student promotion in the US, China, and South Korea, leading to school graduation of up to three or more years earlier than usual (ibid.). Moreover, there are variations in acceleration between primary and secondary education across countries. Particularly in primary education-most often applied as early enrollment-acceleration gained importance in the last years in the Netherlands, while redshirting represents a prominent practice in the US (Heinbokel, 2009; Kretschmann et al., 2014). According to a large amount of US research, acceleration is an effective measure for promoting gifted students. It is cost-effective and avoids upholding gifted students by correcting for a non-optimal placement of their grade level. Studies conclude that the impact on students' achievement is positive, while there is most often no negative or even a positive impact on non-cognitive outcomes such as well-being (Steenbergen$\mathrm{Hu}$ and Moon, 2011). However, longitudinal evidence in the European context indicates that lasting effects of acceleration are questionable since a considerable share of accelerated students experiences grade retention later on (Kretschmann et al., 2014). Beyond that, teachers and parents view acceleration critically and are rather unwilling to participate (Siegle et al., 2013).

In contrast to acceleration, retaining the lowest-achieving students in the same grade for an extra school year is a more widespread practice. In countries such as Portugal, Germany, France, and the Netherlands, retention is common whereas, in Finland, Poland, and Greece, it is applied only exceptionally. In countries such as Norway, South Korea, Iceland, and the UK grade retention is either not allowed or not applied (for an overview of grade retention across OECD countries see Eurydice, 2011). There is extensive research on characteristics of retained students as well as on the effectiveness of retention (for a meta-analysis see Jimerson, 2001). Consistently across studies, low performance is the most important factor of retention. Beyond that, retained students are more often male, of immigrant descent, and comparatively younger than their classmates. They are more often lacking non-cognitive skills and more often absent from school (de Fraine et al., 2012; Kloosterman and de Graaf, 2010). While factors driving grade retention are uncontroversial, the effectiveness of grade retention is more ambivalent. The majority of (meta- 
)studies concludes that retention results in negative attitudes towards school and a greater likelihood to show problematic behavior (Ikeda and García, 2014; Jimerson, 2001). The effects on performance-related outcomes are mixed. The convergence of research demonstrates a shortterm achievement advantage of retained students, especially in the early stages of the educational career. However, there is no performance advantage of retention in the long run and for later stages (Diris, 2017; Silberglitt et al., 2006). Instead, late retention increases the risk of school noncompletion (Jacob and Lefrgen, 2009). Also, the financial resources devoted to retention are extensive. A cross-country comparison states that the costs of grade retention could represent a fraction of the overall costs of primary and secondary education of up to 10 to $12 \%$ in Belgium and the Netherlands and up to 5 to $10 \%$ in Germany and Italy (Ikeda and Garcia, 2014). Evidence concerning social inequality in causes and consequences of acceleration and retention is limited since these forms of internal mobility are mainly studied by psychologists and economists and are much less in the focus of attention of social stratification research.

Grade retention is a widespread practice despite the empirical evidence on possible negative long-term outcomes. This is presumably because retention represents an instrument of power. A major influence of retention lies in the possibility of retention. We argue that the threat of being retained causes students to make an extra effort in order not to fail and lose an entire year. Thus, the potential positive impact might not be observed by comparing retained to non-retained students. This makes it a difficult instrument to evaluate since it raises counterfactual questions about the unintended consequences of (abolishing) retention.

\section{External mobility}

External mobility relates to reallocations in systems that provide hierarchically-structured grouping or tracking. Thus, it refers to secondary education where grouping and tracking are typically applied. This form of mobility describes the change to another ability group or track because students-given their present level of performance-are wrongly placed in the current group or track. In addition, external mobility involves degree stacking. Some tracked education systems provide the possibility to continue in the (next) higher track once the lower educational track is successfully completed with a degree. The major difference between the change of group or track and stacking degrees is that changing groups involves both downgrading and upgrading while stacking degrees represents a particular form of upgrading. Concerning the reallocation of resources, external mobility involves input time $(T)$ and content $(C)$ since changing to another group or track or stacking degrees indicates an extension or reduction of the overall time in school but also a change of learning content. 
There are several studies analyzing the chances to obtain a higher or lower educational degree than offered by the track in which students were initially placed. Empirical studies find that the chances of upgrading are higher for students from higher social origin indicating that the possibility of upgrading exacerbates social inequality instead of decreasing it (Biewen and Tapalaga, 2017; Buchholz and Schier, 2014; Hillmert and Jacob, 2010; Lucas, 2001). In a comparative study, Jacob and Tieben (2009) show that track mobility during secondary education occurs less often in the Netherlands than in Germany and is less strongly associated with social origin. Biewen and Tapalaga (2016) demonstrate in a comprehensive study on educational pathways that although female students are more often initially placed in higher tracks, male students are more likely to upgrade. They also find immigrant students to be slightly more likely to upgrade degrees. Observing both upward and downward mobility between ability groups in US high schools, it could be shown that girls are less likely to upgrade, while black students are more likely to downgrade than whites (Hallinan, 1996). While there is a large number of studies on the consequences of internal mobility-i.e., acceleration and retention-most studies on external mobility employ retrospective data. Thus, the focus is more on the causes rather than on the consequences of track changing and degree stacking. Beyond that, the studies mainly concentrate on upward mobility, while research is less often explicitly focused on downgrading.

\subsection{Flexibility at the meso level}

A large body of educational effectiveness research argues that the success of a school system is determined less by its structure or institutional arrangements than by what effectively takes place in schools and classrooms. Meso level flexibility is strongly associated with standardization at the macro level because flexibility is more likely and more easily applied if the degree of standardization is low. Keeping this in mind, it seems reasonable to argue that macro-level practices of flexibility as discussed above can also play a role at the meso level of schools when standardization is low because single schools or school boards could then apply their own respective rules concerning measures such as changes of tracks or grade retention. In addition to that, we identify distinct measures of flexibility that are related to the curricular organization:

\section{Internal curricular differentiation}

Internal curricular differentiation refers to practices that are applied inside the regular school environment. Practices of so-called "adaptive teaching" require teachers to adjust their instruction on a continuous basis by differentiating with regard to the needs of students 
(Tomlinson, 2014). Thus, teachers can vary the content they present to students. Low-performing students will receive more structured support than high-performing students, who are more capable of working on their own. Internal curricular differentiation relates to the reallocation of content $(C)$ rather than input time $(T)$ since the teacher varies the forms of guidance during regular schooling hours. Even if high-performing students are working more on their own, they are still participating for the same amount of time. It important to evaluate adaptive teaching practices and to apply them in such a way that differentiation of instruction does neither result in holding low-performing students back and increasing individual differences nor in holding highperforming students back by focusing too much on supporting low performers (Kyriakides, 2005). In this context, indicators such as class size and financial and material resources per student but also the denomination of schools play a role. Special schools such as Montessori schools or anthroposophical schools follow principles that are closely related to differentiation and adaptive teaching. A way to respond to the cost of individualized or personalized instruction is the implementation of computer-assisted learning. Empirical studies comparing individualized forms of learning with standard course programs find positive effects of adaptive teaching especially in smaller classes (Brühwiler and Blatchford, 2011).

\section{External curricular differentiation}

External curricular differentiation refers to teaching and learning practices outside the regular school environment but provided by the school ${ }^{3}$. Instruments such as additional educational assistance or supplementary educational services in the form of after-school programs for students with learning deficits, homework assistance or summer school offerings comprise examples of external differentiation. In contrast to internal differentiation, this indicator of flexibility often refers to the reallocation of time $(T)$ rather than content $(C)$ as students are additionally provided with instruction in order to master the regular curriculum. The existence of summer schools or extra learning possibilities often goes hand in hand with the non-existence of grade retention or is viewed as an alternative. Moreover, in some countries, we find the idea of "enrichment" (Heinbokel, 2009) to be in practice. It represents an alternative to grade acceleration and thus refers reallocation of content $(C)$ rather than time $(T)$. Children are supplied with additional learning material in order to deepen and extend their knowledge without shortening time. In the Baltic States and some eastern European countries students who might

\footnotetext{
${ }^{3}$ We are not referring to so-called shadow education or private tutoring since they are not part of the education system. Empirical research has shown that private tutoring is an instrument that is strongly associated with parental involvement and social status (Byun and Baker, 2015).
} 
have to repeat a year are given additional work or lessons at the end of the schoolyear (Eurydice, 2011). Research on the effectiveness of additional tutoring suggests small but considerable achievement gains, however, only in the short run (Rothman and Henderson, 2011). Regarding the relation between retention and summer school attendance, a Dutch study shows that summer school attendance does decrease the likelihood of retention only at later points in the educational career however no lasting performance improvement is observed (Ghysels et al., 2015).

\section{Directions for future research}

In the previous sections we have introduced and elaborated a new concept for educational research: The flexibility of educational systems. The strength of the concept lies in the systematic integration of insights from sociological, psychological, and economic approaches into a common framework, integrating both the meso and macro level. We believe that the concept will help in gaining a deeper understanding of why certain structural characteristics at macro or meso level give mixed results when we look at outcomes. Although the developed framework provides a solid basis, we believe that future research should aim to strengthen the theoretical and empirical aspects of this new concepts.

Theoretically, it is important to develop the framework further. An important aspect is to have a more systematic understanding how different aspects of flexibility relate to each other and under which conditions they act as substitutes or complements. To give some examples:

- Future research should further explore the relation between external mobility and the degree of stratification of an education system. As indicated above, early stratifying systems with frequent and easily accessible possibilities of external mobility should have different implications regarding educational outcomes compared to early stratifying systems in which initial track placement is rather immutable. But what is not clear is which aspects of external mobility have the strongest impact (degree stacking or track mobility?). Neither is clear what the implications are for social inequality in education. Can parents with better knowledge of the educational system, make better use of the possibilities that external mobility offer them, or is external mobility the 'second chance' par excellence for the lower SES groups?

- Future research should also elaborate to which extent internal and external educational mobility can be considered substitutes. In stratified education systems, external mobility represents a common alternative to internal mobility. Downgrading can be applied in order to avoid grade retention and instead of skipping a grade in a low or intermediate track, a 
transfer to a higher track can represent an alternative. This is again, particularly relevant in stratified education systems, where the costly and mostly considered inefficient practice of retention can be avoided by track downgrading. To what extent are these forms of mobility really substitutes? And is there a social gradient in using them (e.g., parents from high SES favouring retention rather than downgrading)?

- A similar question relates to the substitution possibilities of internal and external forms of differentiation. For instance, extracurricular learning opportunities could be unnecessary when adaptive teaching is successfully applied. Moreover, as stated throughout the previous sections, forms of differentiation can complement forms of internal and external mobility. A task for future empirical research is to observe if and how this is realized in different education systems and what the implications for individual educational outcomes are.

It is also important to develop empirical implementations of the framework. As indicated earlier, different aspects of flexibility have been studied before, so the area is not entirely new. The aim of future research however is to systematically address these different indicators from a common theoretical perspective and try to integrate them. This is not without challenges: Even though it is a strength of the concept of flexibility that it links different levels of the education system, it is particularly this link that provides a challenge when analyzing the indicators empirically because they can complement or supplement each other. Possible approaches are:

- Analyzing specific measures and testing the substitution potential: As illustrated above, there is already a considerable number of research focusing on specific aspects of flexibility (e.g., track mobility, grade retention, summer schools, differentiation in the dynamic model of educational effectiveness ((DMEE) etc). We make the case that discussing existing findings from a conceptual perspective of flexibility would further substantiate this research. It is important that future research focuses more on the substitution and complementarity of different flexibility indicators. This is particularly interesting from a policy perspective because this type of research can provide answers to the question whether distinct educational policies (e.g., track mobility or grade retention) can effectively be replaced by forms of differentiated learning (e.g., extra tutoring or summer school programmes).

- Developing overarching indicator(s) of flexibility. Next to analysing the substitution potential of different flexibility indicator, it is good to investigate to what extent an overarching empirical construct can be developed. Latent-factor or latent-class analyses are well-established in school effectiveness research and frequently applied to systemize factors at the meso level (e.g., Kyriakides and Creemers, 2008) or macro level (Bol and van de 
Werfhorst, 2013). However, they are not yet applied to derive concepts that cut across different levels of the educational system. Hence, we suggest making use of these methods to classify different education systems at the meso and the macro level according to their degree of flexibility. In doing so, all indicators presented in section three can be integrated to obtain descriptive information on the degree of flexibility in education systems. The approach can be complemented with an expert survey to rate countries according to their flexibility potential in education. Such a more qualitative survey could be used to cross-validate findings that are gained from the quantitative factor analyses.

\section{Conclusion}

This conceptual contribution aims at introducing flexibility as a key characteristic of education systems. Flexibility is defined as possibilities that are provided by an education system to change standard (predetermined) learning paths, which result from the structured organization of education. We think that the concept of flexibility will provide a fruitful contribution to the research literature on the effects of educational contexts on educational outcomes. The concept is the first to draw systematic attention to constraints and rigidness in the individual educational process or rather the lack of such constraints (flexibility). The idea that educational paths are indeed structured yet not deterministic is not just important for the educational trajectories of individuals. The possibility of flexibility will affect the frame of reference in which individuals plan and pursue their prospective course of education. In a strongly tracked system the sorting into a low track might, for instance, be perceived as less consequential if track mobility is a frequently applied and well-established instrument. Thus, flexibility can contribute to a better understanding of why education systems that are considered similar when focusing on the key features of standardization and stratification nevertheless affect the core functions of education differently.

We argue that aspects of flexibility such as track mobility, classroom differentiation or adaptable teaching have already been discussed in different strands of literature, such as sociological research on features of the education system, psychological literature on educational effectiveness, and economic research drawing on the education production function. However, these strands of research are often not related. We introduced and discussed an overarching concept of flexibility against the background of these strands of literature. Furthermore, we outlined different dimensions of flexibility and proposed corresponding indicators of measurement. We suggested several ways of for future research, both theoretically and empirically. Overall, we argue that different forms of flexibility can have positive or negative effects for the overall educational outcome of students as well as for social 
inequality in education. By making this concept explicit, it becomes possible to study which forms and configurations of flexibility help (or hinder) students' educational outcomes. We believe that our concept contributes to the literature by systematically integrating institutional possibilities of modifying learning paths in the individual educational career. Moreover, our concept stresses the relation and potential trade-off between macro and meso level flexibility. This link is crucial as potential flexibility mechanisms at the macro level are partly mediated at the meso level. And when the degree of standardization is low, rigidities at the macro level can be softened by flexibility in the allocation of educational resources at the meso level. The idea of flexibility requires integrating the different levels of the education system. Neglecting the supplementary or complementary relation between factors at the macro and the meso level could lead to specific mechanisms and effects not being detected before as well as to overestimating or underestimating effects on students' educational outcomes. This strongly relates to the practical relevance of flexibility. Directing the attention of educational decision-makers and practitioners to the relevance of specific configurations of indicators and to the trade-off between specific instruments such as grade retention, track mobility and extra tutoring offerings provides the possibilities to implement educational instruments that are more meaningfully coordinated between macro and meso level.

\section{References}

Allmendinger J (1989) Educational systems and labor market outcomes. European Sociological Review 5(3): 231-250. DOI: 10.1093/oxfordjournals.esr.a036524.

Allmendinger J (2016) Good and bad education systems: Is there an ideal? In: Gross C and Hadjar A (eds) Education Systems and Inequalities. International Comparisons. Bristol: University Press, pp. 321-334. DOI: $10.2307 /$ j.ctt1t892m0.21.

Altinok N and Kingdon G (2012) New Evidence on Class Size Effects: A Pupil Fixed Effects Approach. Oxford Bulletin of Economics and Statistics 74(2): 203-234. DOI: 10.1111/j.14680084.2011.00648.x.

Ammermüller A (2013) Institutional Features of Schooling Systems and Educational Inequality: Cross-Country Evidence From PIRLS and PISA. German EconomicReview 14(2): 190-213. DOI: 10.1111/j.1468-0475.2012.00565.x.

Bernardi F (2014) Compensatory Advantage as a Mechanism of Educational Inequality: A Regression Discontinuity Based on Month of Birth. Sociology of Education 87(2): 74-88. DOI: 10.1177/0038040714524258.

Biewen M and Tapalaga M (2017) Life-cycle educational choices in a system with early tracking and 'second chance' options. Economics of Education Review 56: 80-94. DOI:

10.1016/j.econedurev.2016.11.008. 
Bol T and van de Werfhorst HG (2013) Educational Systems and the Trade-Off between Labor Market Allocation and Equality of Educational Opportunity. Comparative Education Review 57(2): 285-308. DOI: 10.1086/669122.

Bol T and van de Werfhorst HG (2016) Measuring educational institutional diversity: External differentiation, vocational orientation and standardization. In: Gross C and Hadjar A (eds) Education Systems and Inequalities. International Comparisons. Bristol: University Press, pp. 73-93. DOI: $10.2307 / \mathrm{j} . \mathrm{ctt} 1 \mathrm{t} 892 \mathrm{~m} 0.21$.

Brühwiler C and Blatchford P (2011) Effects of class size and adaptive teaching competency on classroom processes and academic outcome. Learning and Instruction 21(1): 95-108. DOI: 10.1016/j.learninstruc.2009.11.004.

Brunello G and Checchi D (2007) Does school tracking affect equality of opportunity? New international evidence. Economic Policy 22(52): 782-861. DOI: 10.1111/j.1468-0327.2007.00189.x.

BuchholzS and Schier A (2014) New Game, New Chance? Social Inequalities and Upgrading Secondary School Qualifications in West Germany. European Sociological Review 31(5): 603-615. DOI: $10.1093 /$ esr/jcv062.

Byun SY and Baker DP (2015) Shadow Education. In: Emerging Trends in the Social and Behavioral Sciences. 1-9. DOI: 10.1002/9781118900772.etrds0301.

Collier VP (1989) How Long? A Synthesis of Research on Academic Achievement in a Second Language. TESOL Quarterly 23(3): 509. DOI: 10.2307/3586923.

Coleman, JS (1990) Foundations of social theory. Cambridge: Harvard University Press.

Creemers BPM and Reezigt GJ (1996) School level conditions affecting the effectiveness of instruction. School Effectiveness and School Improvement 7(3): 197-228.

De Fraine B, Goos M, Trautwein U, et al. (2012) How Can Cross-Country Differences in the Practice of Grade Retention Be Explained? A Closer Look at National Educational Policy Factors. Comparative Education Review 57(1): 54-84. DOI: 10.1086/667655.

Denney NW (1984) A model of cognitive development across the life span. Developmental Review 4(2): 171-191. DOI: 10.1016/0273-2297(84)90006-6.

Diris R (2017) Don't Hold Back? The Effect of Grade Retention on Student Achievement. Education Finance and Policy 12(3): 312-341. DOI: 10.1162/EDFP_a_00203.

Dronkers J and Robert P (2008) School Choice in the Light of the Effectiveness Differences of Various Types of Public and PrivateSchools in 19 OECD Countries. Journal of School Choice 2(3): 260-301. DOI: 10.1080/15582150802371499.

Eurydice (2011) Grade Retention during Compulsory Education in Europe: Regulations and Statistics. DOI: $10.2797 / 50570$.

Ghysels J, Haelermans C and Monfrance M (2015) The effect of summer schools on grade retention in Dutch secondaryeducation: A regression discontinuity approach. Working paper. 
Gross C, Meyer H-D and Hadjar A (2016) Theorising the impact of education systems on inequalities In: Gross C and Hadjar A (eds) Education Systems and Inequalities. International Comparisons.

Bristol: University Press, pp. 11-31. DOI: 10.2307/j.ctt1t892m0.21.

Gross MUM and van Vliet HE (2005) Radical Acceleration and Early Entry to College: A Review of the Research. Gifted Child Quarterly 49(2): 154-171. DOI: 10.1177/001698620504900205.

Hallinan MT (1996) Race effects on students' track mobility in high school. Social Psychologyof Education 1(1): 1-24. DOI: 10.1007/BF02333403.

Hanushek EA (1979) Conceptual and Empirical Issues in the Estimation of Educational Production Functions. Journal of Human Resources 14(3): 351-388.

Hanushek EA and Wößmann L (2005) Does Educational Tracking AffectPerformance and Inequality? ZEW-Working Paper.

Hattie J (2008) Visible Learning: A Synthesis of over 800 Meta-Analyses Relating to Achievement. London: Routledge, Abingdon.

Heinbokel A (2009) Handbuch Akzeleration: Was Hochbegabten Nützt. Muenster: LIT Verlag.

Hillmert S (2004) Soziale Ungleichheit im Bildungsverlauf: zum Verhältnis von Institutionen und Entscheidungen. In: Becker, Rolf/Lauterbach, Wolfgang(eds): Bildung als Privileg? Ursachen von Bildungsungleichheitaus soziologischer Sicht. Wiesbaden: VS Verlag, pp. 69-97.

Hillmert S and Jacob M (2005) Zweite Chance im Schulsystem? In: Berger PA (ed) Institutionalisierte Ungleichheiten. Weinheim, München: Juventa.

Hillmert S and Jacob M (2010) Selections and social selectivity on the academic track: A life-course analysis of educational attainment in Germany. Research in Social Stratification and Mobility 28(1): 59-76. DOI: 10.1016/j.rssm.2009.12.006.

Ikeda M and García E (2014) Grade repetition: A comparative study of academic and non-academic consequences. OECD Journal: Economic Studies 2013(1): 269-315. DOI: 10.1787.

Jacob BA and Lefgren L (2009) The Effect of Grade Retention on High School Completion. American EconomicJournal: Applied Economics 1(3): 33-58. DOI: 10.1257/app.1.3.33

Jacob M and Tieben N (2009) Social selectivity of track mobility in secondary schools: A comparison of intra-secondary transitions in Germany and The Netherlands. European Societies 11(5): 747-773. DOI: $10.1080 / 14616690802588066$.

Jimerson SR (2001) Meta-analysis of Grade Retention Research: Implications for Practice in the 21st Century. School Psychology Review 30(3): 420-437.

Kloosterman R and de Graaf PM (2010) Non-promotion or enrolment in a lower track? The influence of social background on choices in secondary education for three cohorts of Dutch pupils. Oxford Review of Education 36(3): 363-384. DOI: 10.1080/03054981003775244.

Knudsen EI, Heckman JJ, Cameron JL, et al. (2006) Economic, neurobiological, and behavioral perspectives on building America's future workforce. Proceedings of the National Academy of Sciences 103(27): 10155-10162. DOI: 10.1073/pnas.0600888103. 
Korthals R (2015) Tracking Students in Secondary Education: Consequences for Student Performance and Inequality. PhD thesis. Maastricht University.

Kozulin A, Gindis B, Ageyev VS, et al. (2003) Vygotsky's Educational Theory in Cultural Context. Cambridge: University Press.

Kretschmann J, Vock M and Lüdtke O (2014) Acceleration in elementary school: Using propensity score matching to estimate the effects on academic achievement. Journal of Educational Psychology 106(4): 1080-1095. DOI: 10.1037/a0036631.

Kyriakides L (2005) Extending the Comprehensive Model of Educational Effectiveness by an Empirical Investigation. School Effectiveness and School Improvement 16(2): 103-152. DOI: $10.1080 / 09243450500113936$

Kyriakides L and Creemers BPM (2008) Using a multidimensional approach to measure the impact of classroom-level factors upon student achievement: A study testing the validity of the dynamic model. School Effectiveness and School Improvement 19(2): 183-205. DOI:

10.1080/09243450802047873.

Lucas SR (2001) Effectively Maintained Inequality: Education Transitions, Track Mobility, and Social Background Effects. American Journal of Sociology 106(6): 1642-1690. DOI: 10.1086/321300.

Morgan H (2014) Review of Research: The Education System in Finland: A Success Story Other Countries Can Emulate. Childhood Education 90(6): 453-457. DOI:

10.1080/00094056.2014.983013.

Pfeffer FT (2015) Equality and quality in education. A comparative study of 19 countries. Social Science Research. 51: 350-368. DOI: 10.1016/j.ssresearch.2014.09.004.

Piaget J (1952) The Origins of Intelligence in Children. New York: International Universities Press.

Rothman T and Henderson M (2011) Do School-Based Tutoring Programs Significantly Improve Student Performance on Standardized Tests? RMLE Online 34(6): 1-10. DOI:

10.1080/19404476.2011.11462079.

Scheerens J and Bosker RJ (1997) The Foundations of Educational Effectiveness. Oxford: Pergamon.

Shavit Y and Müller W (1998) From School to Work: A Comparative StudyofEducational Qualifications and Occupational Destinations. Oxford: Clarendon Press.

Siegle D, Wilson HE and Little CA (2013) A Sample of Gifted and Talented Educators' Attitudes About Academic Acceleration. Journal of Advanced Academics 24(1): 27-51. DOI: 10.1177/1932202X12472491.

Silberglitt B, Appleton JJ, Burns MK, et al. (2006) Examining the effects of grade retention on student reading performance: A longitudinal study. Journal of School Psychology 44(4): 255-270. DOI: 10.1016/j.jsp.2006.05.004.

Steenbergen-Hu S and Moon SM (2011) The effects of acceleration on high-ability learners: A metaanalysis. Gifted Child Quarterly 55(1): 39-53. DOI: 10.1177/0016986210383155.

Teddlie C and Reynolds D (2000) The International Handbook ofSchool Effectiveness Research. London: Falmer Press. 
Tomlinson CA (2014) The Differentiated Classroom. Responding to the Needs of All Learners. Alexandria: ASCD.

Van de Werfhorst HG and Mijs JJB (2010) Achievement Inequality and the Institutional Structure of Educational Systems: A Comparative Perspective. Annual Review of Sociology 36(1): 407-428. DOI: 10.1146/annurev.soc.012809.102538.

Van der Velden RKW and Wolbers MHJ (2003) The integration of young people into the labour market: the role of training systems and labour market regulation. In: Transitions from Education to Work in Europe. Oxford University Press, pp. 186-211. DOI: 10.1093/0199252475.003.0007.

Verachtert P, de Fraine B, Onghena P, et al. (2010) Season of birth and school success in the early years of primary education. Oxford Review of Education 36(6): 2085-306. DOI:

10.1080/03054981003629896.

Wößmann L (2016) The Importance of School Systems: Evidence from International Differences in Student Achievement. Journal of Economic Perspectives 30(3): 3-32. DOI: 10.1257/jep.30.3.3. 


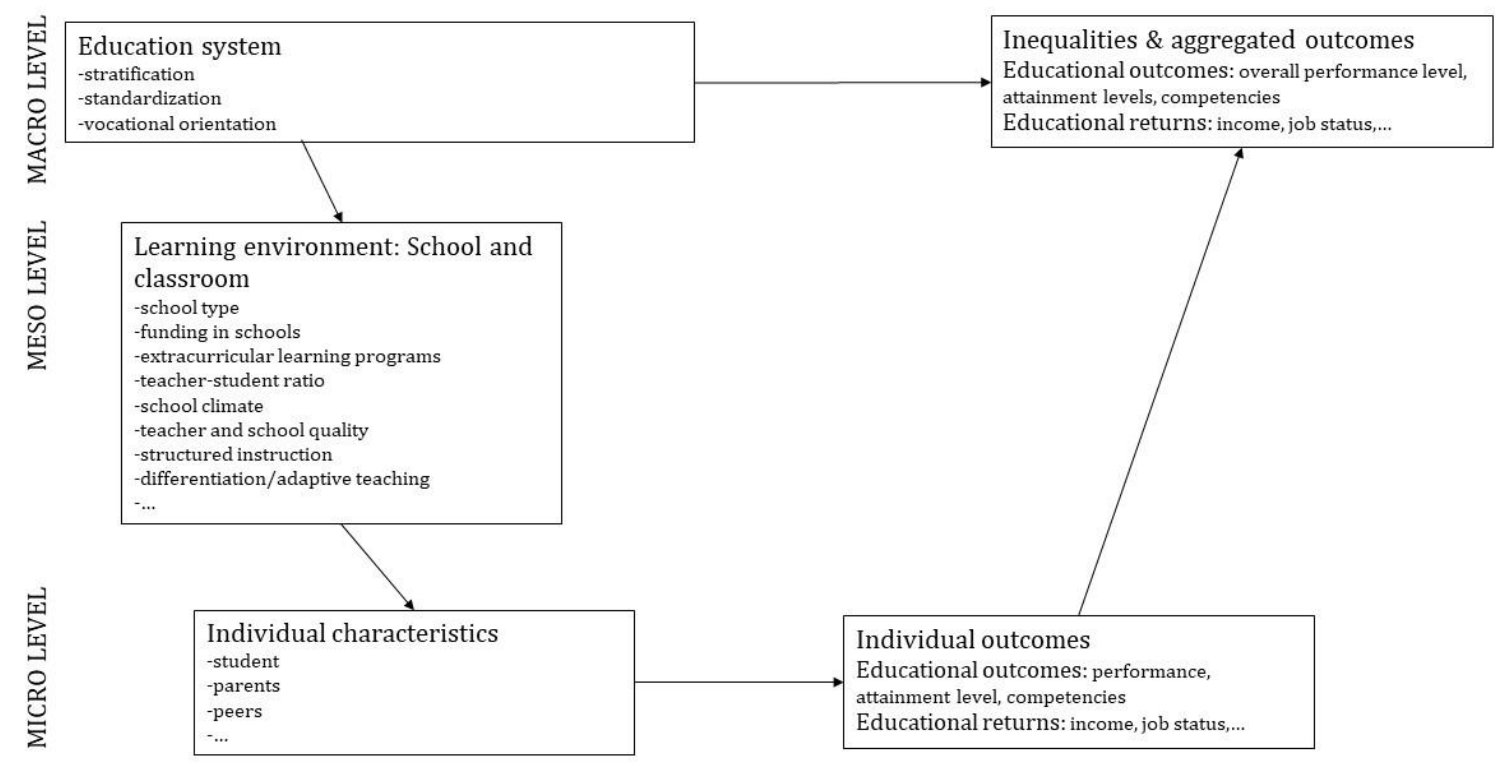

Figure 1. Macro-meso-micro model (cf. Gross et al., 2016) 


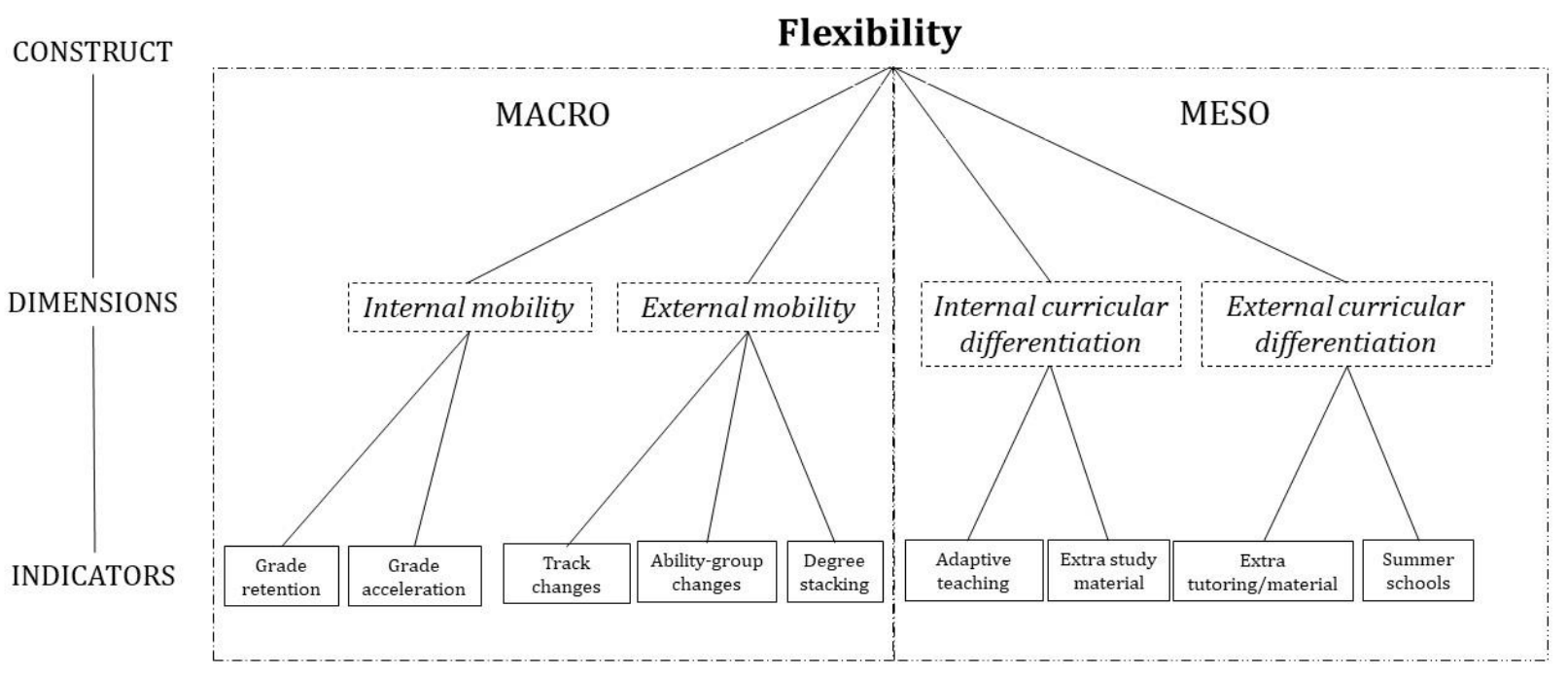

Figure 2. Conceptual model of flexibility in education 